\title{
Estimation of surface Latent Heat Fluxes from IRS-P4/MSMR satellite data
}

\author{
Randhir Singh, B Simon and P C Joshi \\ Atmospheric Sciences Division, Meteorology 83 Oceanography Group, Space Applications Centre, ISRO \\ Ahmedabad 380 015, India.
}

The brightness temperatures of the Microwave sensor MSMR (Multichannel Scanning Microwave Radiometer) launched in May 1999 onboard Indian Oceansat-1 IRS-P4 are used to develop a direct retrieval method for latent heat flux by multivariate regression technique. The MSMR measures the microwave radiances at 8 channels at frequencies of 6.6, 10.7, 18 and $21 \mathrm{GHz}$ at both vertical and horizontal polarizations. It is found that the surface LHF (Latent Heat Flux) is sensitive to all the channels. The coefficients were derived using the National Centre for Environmental Prediction (NCEP) reanalysis data of three months: July, September, November of 1999. The NCEP daily analyzed latent heat fluxes and brightness temperatures observed by MSMR were used to derive the coefficients. Validity of the derived coefficients was checked with in situ observations over the Indian Ocean and with NCEP analyzed LHF for global points. The LHF derived directly from the MSMR brightness temperature $(\mathrm{Tb})$ yielded an accuracy of $35 \mathrm{watt} / \mathrm{m}^{2}$. LHF was also computed by applying bulk formula using the geophysical parameters extracted from MSMR. In this case the errors were higher apparently due to the errors involved in derivation of the geophysical parameters.

\section{Introduction}

Evaporation at the air-sea interface results in the transport of energy and water vapour into the atmosphere. The energy transport partly compensates losses of energy through radiation processes in the atmosphere. The global mean of this energy transport is equivalent to $26 \%$ of the incoming solar energy at the top of the atmosphere. On this account, the exchange of energy between the sea surface and atmosphere is a major energy source for the atmospheric circulation. The exchange of water vapour and heat at the sea surface takes place simultaneously and connects the energy cycle to the hydrological cycle. Thus the surface latent heat flux (LHF) causes cooling of the upper layer of the ocean and, through the loss of water vapour, an increase of salinity in the ocean mixed layer. Accurate estimates of LHF at the sea surface (together with other heat fluxes, momentum flux and precip- itation) with global coverage is a very useful input for verifying coupled ocean-atmosphere models, as well as driving ocean models.

The direct way to obtain the surface turbulent fluxes is using the eddy correlation technique. However from the surface bulk meteorological observations (near-surface wind speed, air humidity, sea surface temperature) the fluxes are usually computed using the bulk-aerodynamic method using the equation:

$$
L_{E}=\rho E C_{D}\left(u_{s}-u_{a}\right)\left(q_{s}-q_{a}\right)
$$

The subscript ' $a$ ' corresponds to a reference altitude, ' $s$ ' stands for surface quantities, ' $C_{D}$ ' is the bulk transfer coefficient, ' $q$ ' is the specific humidity, ' $u$ ' the scalar wind and ' $\rho$ ' and ' $E$ ' are constants. The transfer coefficient parameterization needed in the bulk calculation is selected among the numerous existing models (e.g. Large and

Keywords. Multi-frequency Scanning Microwave Radiometer (MSMR); Latent heat flux (LHF); National Centre for Environmental Prediction (NCEP). 
Pond 1982). This method is based on the MoninObukhov (1954) similarity theory.

Limited in situ measurements of LHF are available over the globe. The only solution to get realtime global coverage is by the use of space borne sensors, insofar as they already provide operational measurements of geophysical parameters related to the LHF such as the sea surface temperature (SST), the columnar water vapour and near surface wind speed. There are a number of studies (e.g. Schulz 1996; Joshi and Simon 1993) for estimating latent heat flux from satellite data. Liu and Niiler (1984) and Liu (1986) applied the bulk formula to retrieve the surface LHF using near surface parameters derived from satellite data. This method, hereafter referred to as the LN method, uses geophysical parameters such as winds, sea surface temperature and surface specific humidity retrieved using data from sensors operating at microwave frequencies.

When applying the LN method to data averaged over one month and two square degrees in space, Esbensen et al (1993) and Eymard et al (1989) find error close to $30 \mathrm{~W} / \mathrm{m}^{2}$ in average. They notice that $100 \mathrm{~W} / \mathrm{m}^{2}$ error can be found locally for particular climatic locations or bad radiometric calibration zones. Among the different sources of error, the wind retrieval is still a problem for using satellite data such as SSM/I and retrieval of $q$ is noisy. Singh et al (2000) have demonstrated that the surface specific humidity over oceans can be determined using MSMR channel radiances up to RMS accuracy of $1.4 \mathrm{~g} / \mathrm{kg}$. The errors can be reduced if LHF is obtained directly from microwave radiometer brightness temperature.

In the present study we have developed a model to derive surface latent heat flux directly from brightness temperatures (Tb) of IRS-P4/MSMR. This approach has a distinct advantage over the conventional method of estimation of LHF. It enables us to compute LHF on an instantaneous basis. For retrieval of LHF, we analyzed the data and found a relationship between MSMR Tb and LHF through a multi-linear regression technique. The specifications of MSMR channels are described in section 2. The methodology, retrieval technique and results are described in sections 3,4 and 5 respectively.

\section{MSMR specifications}

India has launched several remote sensing satellites under the series of IRS satellites. IRS-P4 satellite is the fourth satellite launched by the launch vehicle PSLV from Sriharikota, India. IRS-P4 was launched in May, 1999 and is sun-synchronous, near polar and has a near circular orbit at an altitude of $720 \mathrm{~km}$ with local time of equator cross-
Table 1. Specifications of IRS-P4 and MSMR.

\begin{tabular}{ll}
\hline Satellite & \\
\hline Altitude & $720 \mathrm{~km}$ \\
Swath & $1360 \mathrm{~km}$ \\
Repetivity & 2 days \\
Orbit inclination & $98^{\circ}$ \\
& \\
MSMR & $65 \mathrm{~kg}$ \\
Weight & $6.6,10.7,18,21 \mathrm{GHz}$ \\
Frequency & $\mathrm{V} \& \mathrm{H}$ \\
Polarization & 40 to $120 \mathrm{~km}$ \\
Spatial resolution & $1^{\circ} \mathrm{K}$ \\
Temperature resolution &
\end{tabular}

Table 2. Accuracies of geophysical parameters for IRS-P4/MSMR.

\begin{tabular}{lc}
\hline \multicolumn{1}{c}{ Parameters } & Accuracies \\
\hline Total water vapour $\left(\mathrm{g} / \mathrm{cm}^{2}\right)$ & 0.3 \\
Sea surface wind $(\mathrm{m} / \mathrm{s})$ & 2 \\
Sea surface temperature $(\mathrm{k})$ & 1.5 \\
Cloud liquid water $\left(\mathrm{mg} / \mathrm{cm}^{2}\right)$ & 13.6 \\
\hline
\end{tabular}

ing in descending node at $1200 \mathrm{hrs}$. The Multichannel Scanning Microwave Radiometer (MSMR) onboard IRS P4 with a capability of global coverage with two day repetitivity has been providing data since its launch. MSMR is an eight band (four frequency in dual polarizations) passive microwave radiometer with a conical scan mechanism (table 1 ). The frequency combination of MSMR, 6.6, 10.7, 18 and $21 \mathrm{GHz}$, facilitates generation of geophysical parameters - total water vapour in the marine atmosphere, sea surface wind speed, sea surface temperature and total cloud liquid water as shown in table 2 (Gohil et al 2000). The retrieved parameters have been validated by an extensive sea-truth collection programme and the results are summarized in table 2 .

\section{Data used}

In this study three data sets have been used:

- The daily NCEP (National Center for Environmental Prediction) analyzed latent heat flux from June - December 1999. This data set is represented by the Gaussian grid of 94 lines from equator to each pole with a regular $1.8^{\circ}$ longitudinal spacing. The data set was projected into $2^{\circ}$ latitude by $2^{\circ}$ longitude grid.

- Daily MSMR brightness temperature (Tb) obtained for the period of June - December 1999 was used. These Tb data were also converted into $2^{\circ}$ latitudes by $2^{\circ}$ longitudes. These data were the GRID-1 type that has $150 \mathrm{~km}$ resolution and all the channels observations. The geophysical 
Table 3. Source of in situ observations.

\begin{tabular}{lll}
\hline No. & \multicolumn{1}{c}{ Time-Period } & \multicolumn{1}{c}{ Location } \\
\hline 1 & 15th June - 12th July 1999 & Indian Ocean \\
2 & 15th July - 25th July 1999 & Bay of Bengal \\
3 & 16th July - 08th August 1999 & Bay of Bengal \\
4 & 10th August - 28th August 1999 & Bay of Bengal \\
\hline
\end{tabular}

parameters (SST, wind and near surface specific humidity) for the three month period (June August 1999) were used to compute LHF using bulk formula. Land was masked by setting suitable thresholds of $6.6 \mathrm{GHz}$ vertical and horizontal brightness temperatures.

- Ship measurements of surface meteorological parameters were used to get latent heat flux for validation purposes. To get latent heat flux from surface meteorological parameters we have used bulk formula given in the equation (1). The ship measured surface meteorological parameters were from four field experiments over Indian Ocean as well as over Bay of Bengal during June - August 1999 and are described in table 3.

(According to Smith (1999) the LHF from NCEP) is accurate to $10-30 \mathrm{watt} / \mathrm{m}^{2}$. We have also compared the NCEP analyzed LHF over Indian Ocean with in situ observed LHF during the period June - August 1999. We found that the RMS error is of the order of $34 \mathrm{~W} / \mathrm{m}^{2}$ between NCEP analyzed LHF and in situ measured LHF. Based on these comparisons we have used NCEP produced LHF in our study.

\section{Retrieval technique}

The algorithm to derive LHF is performed in two stages. First, a large database of MSMR Tb has been generated. Then the generated $\mathrm{Tb}$ for all the frequencies and with both polarizations is correlated with NCEP analyzed LHF.

Stepwise multivariate regression (Draper and Smith 1981) was used to relate surface latent heat flux (LHF) with the relevant brightness temperature:

$$
\mathrm{LHF}=C_{0}+\sum_{i=1}^{i=8} C_{i} T_{i},
$$

where $T_{i}$ is the brightness temperature. The data of MSMR channels at $6,10.7,18$ and $21 \mathrm{GHz}$ with vertical polarization were found to be strongly correlated in comparison to horizontal polarization. LHF is a function of wind speed, near surface specific humidity and saturation specific humidity (as seen in bulk formula). The saturation specific humidity is a function of SST. MSMR measured
Table 4. Correlation between MSMR observed $T b$ and NCEP analyzed latent heat flux.

\begin{tabular}{ccc}
\hline Frequency & $\mathrm{C}(\mathrm{Tb}, \mathrm{LHF})$ & Ranges of $\mathrm{Tb}$ \\
\hline $6.6 \mathrm{GHz} \mathrm{V}$ & 0.84 & $145-160$ \\
$6.6 \mathrm{GHz} \mathrm{H}$ & 0.60 & $78-100$ \\
$10.7 \mathrm{GHz} \mathrm{V}$ & 0.75 & $150-170$ \\
$10.7 \mathrm{GHz} \mathrm{H}$ & 0.52 & $85-110$ \\
$18 \mathrm{GHz} \mathrm{V}$ & 0.67 & $170-200$ \\
$18 \mathrm{GHzH}$ & 0.56 & $100-165$ \\
$21 \mathrm{GHz} \mathrm{V}$ & 0.64 & $180-240$ \\
$21 \mathrm{GHz} \mathrm{H}$ & 0.63 & $115-210$ \\
\hline
\end{tabular}

brightness temperature at $6.6 \mathrm{GHz}$ is sensitive to SST, $10.7 \mathrm{GHz}$ channel is sensitive to wind speed and 18 and $21 \mathrm{GHz}$ channels are sensitive to the water vapour and LHF is parameterized in terms of all these parameters therefore LHF is sensitive to all the channels. It is also to be noted that the relationship between $\mathrm{Tb}$ and LHF is not linear in case of water vapour (18 and $21 \mathrm{GHz}$ frequency). As a first order we have used the linear approximation for these also. Addition of non linear terms will certainly improve the LHF estimation accuracy.

But removal of any channel from the regression strongly affected the accuracy of the retrieved LHF, hence all the channels were included. The final form of the regression equation is as follows:

$$
\begin{aligned}
\mathrm{LHF}= & C_{0}+C_{1} T_{6}^{V}+C_{2} T_{6}^{H}+C_{3} T_{10}^{V}+C_{4} T_{10}^{H} \\
& +C_{5} T_{18}^{V}+C_{6} T_{18}^{H}+C_{7} T_{21}^{V}+C_{8} T_{21}^{H}
\end{aligned}
$$

where $T_{i}^{j}$ is the MSMR brightness temperature with $i$ th frequency and $j$ th polarization. The correlation coefficients between MSMR Tb and LHF along with the range of $\mathrm{Tb}$ for which the derived coefficients are applicable are given in table 4 . Figures $1(\mathrm{a}-\mathrm{h})$ show the scatter plots between NCEP analyzed LHF and MSMR Tb for different frequencies and polarization.

Values of the derived regression coefficients for equation (2) are found to be:

$$
\begin{aligned}
C_{0}= & -2192\left(\text { watt } \mathrm{m}^{-2}\right), C_{1}=23.40\left(\text { watt } \mathrm{m}^{-2}\right. \\
& \left.\mathrm{K}^{-1}\right), C_{2}=-3.89\left(\text { watt } \mathrm{m}^{-2} \mathrm{~K}^{-1}\right), \\
C_{3}= & 1.30\left(\text { watt } \mathrm{m}^{-2} \mathrm{~K}^{-1}\right), C_{4}=-5.95\left(\text { watt } \mathrm{m}^{-2}\right. \\
& \left.\mathrm{K}^{-1}\right), C_{5}=-8.00\left(\text { watt } \mathrm{m}^{-2} \mathrm{~K}^{-1}\right), \\
C_{6}= & 11.20\left(\text { watt } \mathrm{m}^{-2} \mathrm{~K}^{-1}\right), C_{7}=0.40\left(\text { watt } \mathrm{m}^{-2}\right. \\
& \left.\mathrm{K}^{-1}\right) \text { and } C_{8}=-3.40\left(\text { watt } \mathrm{m}^{-2} \mathrm{~K}^{-1}\right) .
\end{aligned}
$$

The coefficients were derived using the data for the months of July, September and November 1999. These data account for all types of earth's atmospheric variability. For example during this period LHF was varied from $10 \mathrm{~W} / \mathrm{m}^{2}$ 


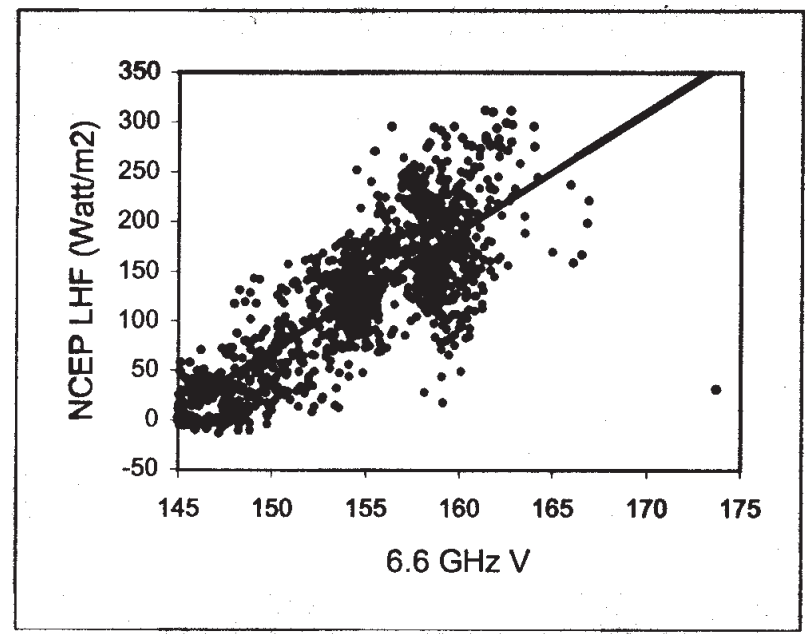

Fig-1a

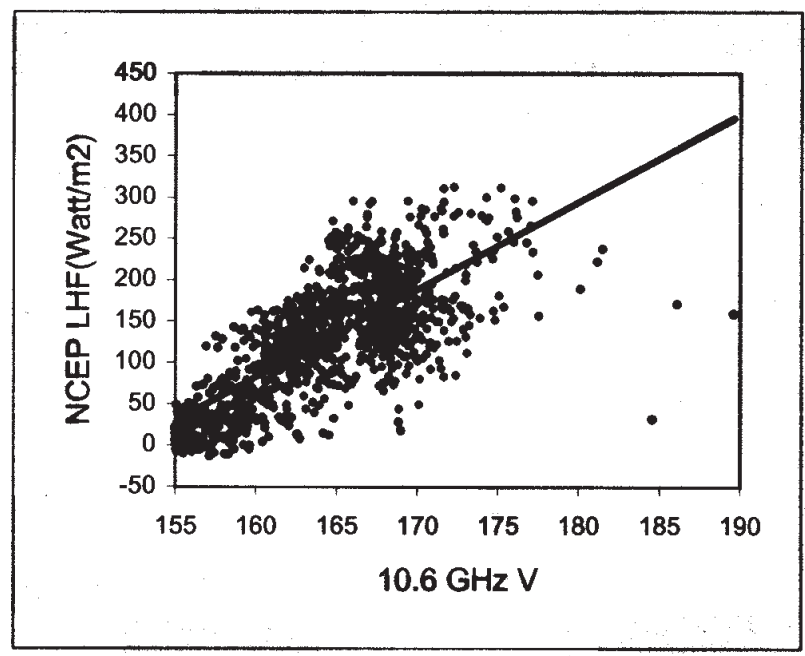

Fig-1c

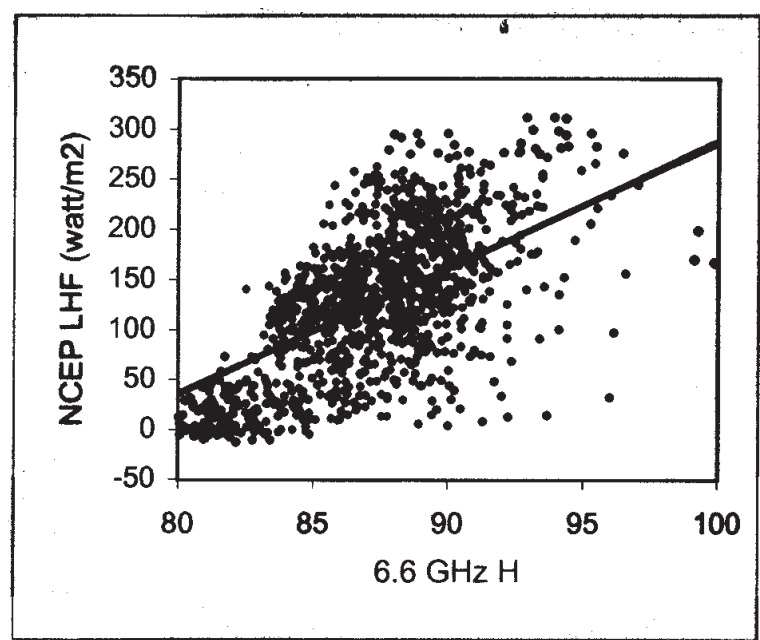

Fig-1b

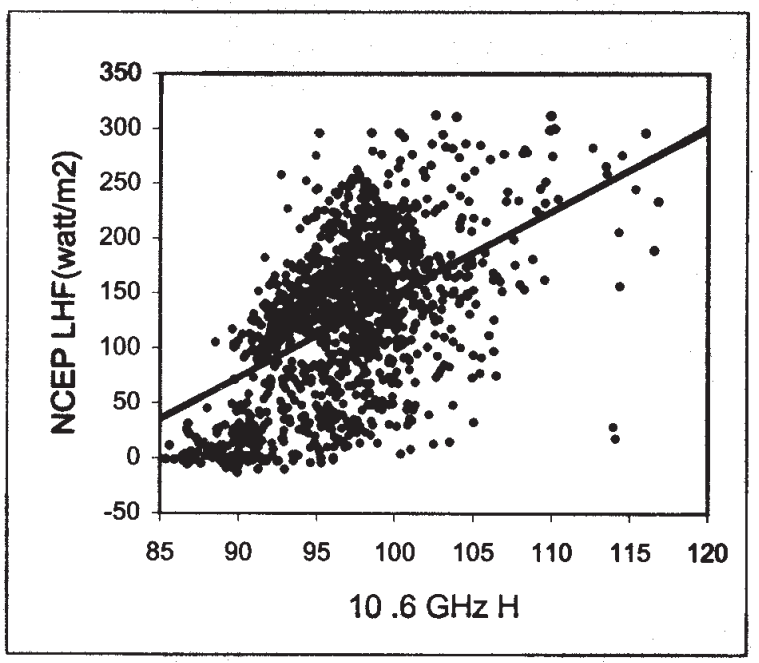

Fig-1d

Figure 1. (a) The scatter plot between NCEP analyzed surface latent heat flux and MSMR observed brightness temperature for $6.6 \mathrm{GHz}$ vertical polarization; (b) Same as figure 1(a) but for horizontal polarization; (c) Same as figure 1(a) but for 10.7 GHz vertical polarization; (d) Same as figure 1(c) but for horizontal polarization.

to $325 \mathrm{~W} / \mathrm{m}^{2}$. To validate this retrieval we compared the MSMR measurements within a distance of $50 \mathrm{~km}$ from the location of in situ surface measurements. This comparison criteria was met in 43 cases within a period of three months over the Indian Ocean. These 43 cases of in situ measurements over the Indian Ocean were taken under four field experiments for IRS-P4 data validation cruises as shown in table 3 .

\section{Validation and discussions}

As discussed above, to validate the retrieved latent heat flux we have adopted the comparison criteria that the in situ measurements should be within $50 \mathrm{~km}$ from MSMR measurements and within \pm 3 hrs time window. The comparison criteria was met in 43 cases (in situ measurements) over the Indian Ocean. The developed retrieval regression model is applied to global MSMR-Tb during the three month period (June - August 1999) with the spatial resolution of $2^{\circ} \times 2^{\circ}$ lat/lon grid. Figure 2(a) shows the global distribution NCEP analyzed surface LHF on 23rd August 1999. Figure 2(b) shows the surface LHF retrieved from MSMR Tb using the developed regression model for the same period. The gaps in figure 2(b) are because the MSMR takes two days for global coverage and also we are not taking the pixels very near to the land. From figure 2(b) high LHF is noticed in the trade wind regions that are larger on summer hemisphere due to larger humidity gradient and high winds. Pockets of maximum LHF have been picked very well by the algorithm. The noticeable point is that the MSMR retrieved LHF has maximum magnitude up to $300 \mathrm{Wm}^{-2}$ in Bay of Bengal and 


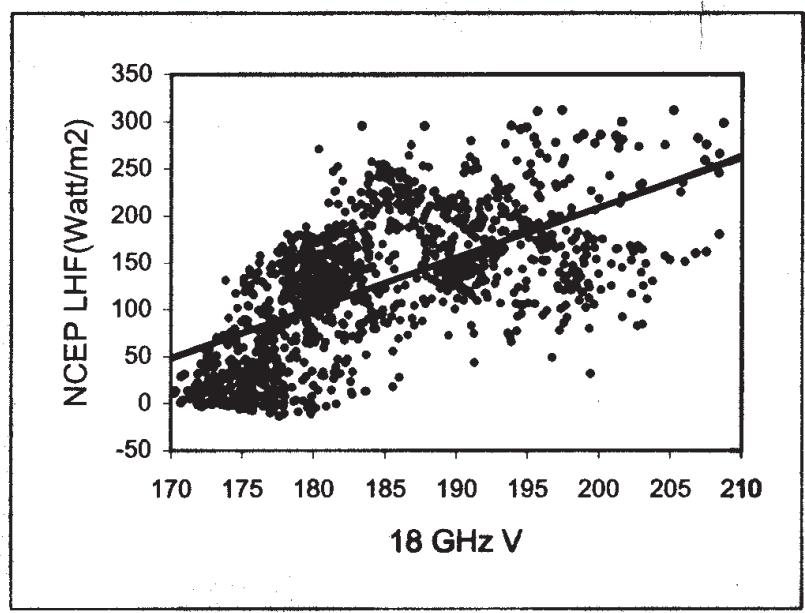

Fig-1e

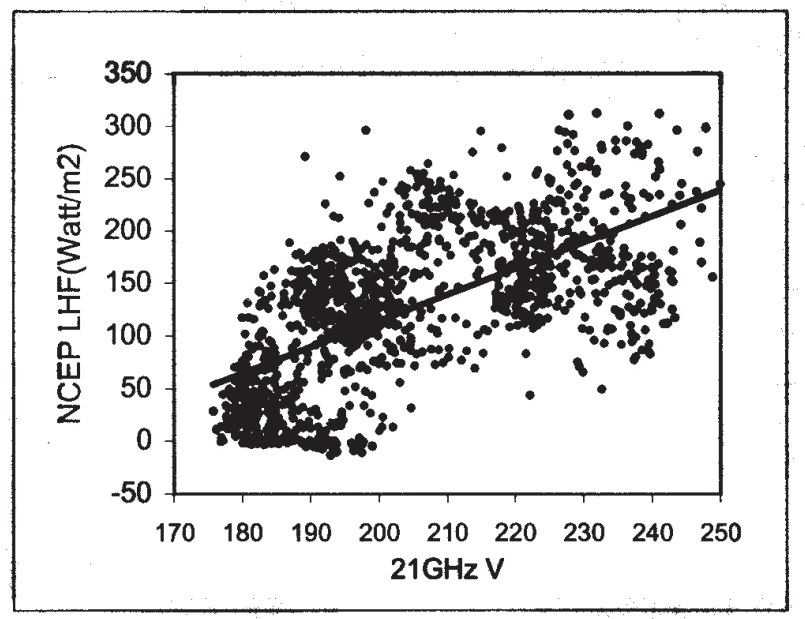

Fig-1g

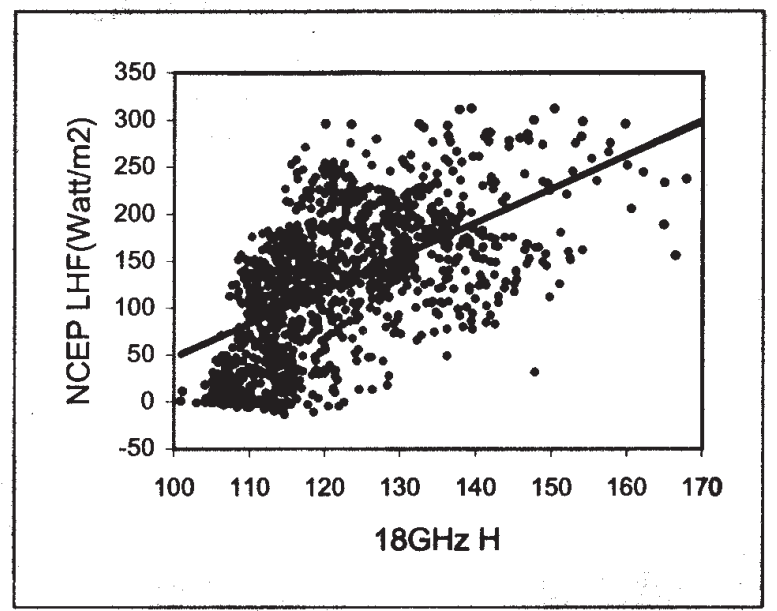

Fig-1f

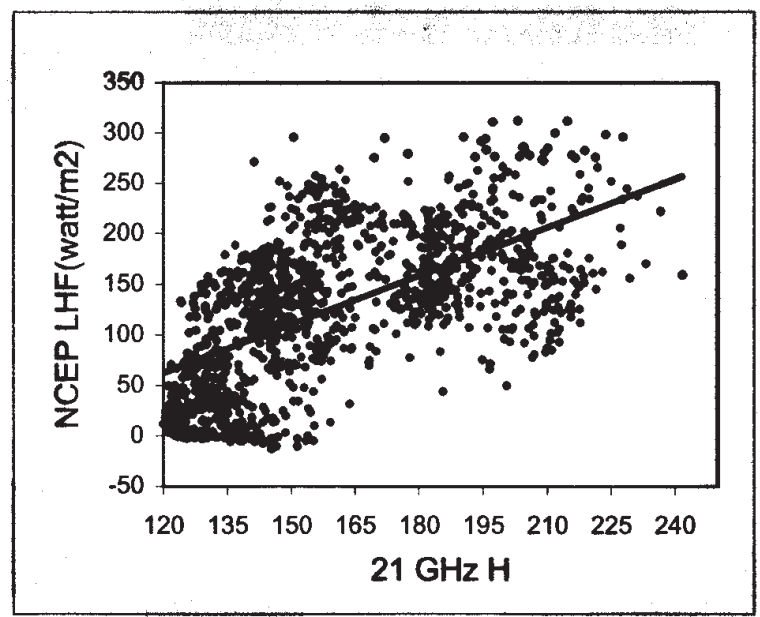

Fig-1h

Figure 1. (e) Same as figure 1(a) but for $18 \mathrm{GHz}$ vertical polarization; (f) Same as figure 1(e) but for horizontal polarization; (g) Same as figure 1(a) but for $21 \mathrm{GHz}$ vertical polarization; (h) Same as figure 1(g) but for horizontal polarization.

in central Indian Ocean while the NCEP analyzed LHF is about $350 \mathrm{Wm}^{2}$ (over Madagascar and Bay of Bengal regions) during the summer monsoon period. Estimated flux thus saturates at 300 watt $\mathrm{m}^{-2}$ leading to the underestimation of fluxes. However the gradients and all the other features have been well picked up by MSMR retrieved LHF.

We have also examined the differences between LHF retrieved directly from MSMR Tb and computed by the bulk formula using geophysical parameters available from MSMR. LHF for the three months period (June - August 1999) were computed using bulk formula (equation1). The geophysical parameters used in this expression have been retrieved (Gohil et al 2000) from MSMR brightness temperatures. The accuracy of these geophysical parameters are given in table 2 . The surface specific humidity $(q)$ used in the formula is retrieved (Singh et al 2000) directly from $\mathrm{Tb}$ rather than from total integrated water vapour. The accuracy of retrieved surface specific humidity $(q)$ is of the order of $1.4 \mathrm{~g} / \mathrm{kg}$. Based on the accuracy mentioned in table 2 we have estimated the corresponding error in the LHF. The MSMR LHF accuracy obtained by applying the GPD (Geophysical data) accuracies on bulk formula is around 60 watt $/ \mathrm{m}^{2}$. Figure 2(c) shows the computed LHF for the period 23rd August 1999 using bulk formula. From figure 2(b) and 2(c) the differences between computed LHF and NCEP analyzed LHF is more than $80 \mathrm{~W} / \mathrm{m}^{2}$ on an average. But locally (central Indian Ocean) the differences of more than $200 \mathrm{~W} / \mathrm{m}^{2}$ have been found. From figure 2(a) and 2(b) the differences between NCEP analyzed LHF and LHF retrieved direct from MSMR $\mathrm{Tb}$ are in the range $-30 \mathrm{Wm}^{-2} \leq \Delta \mathrm{LHF} \leq 30 \mathrm{Wm}^{-2}$. Although in particular regions differences of the 


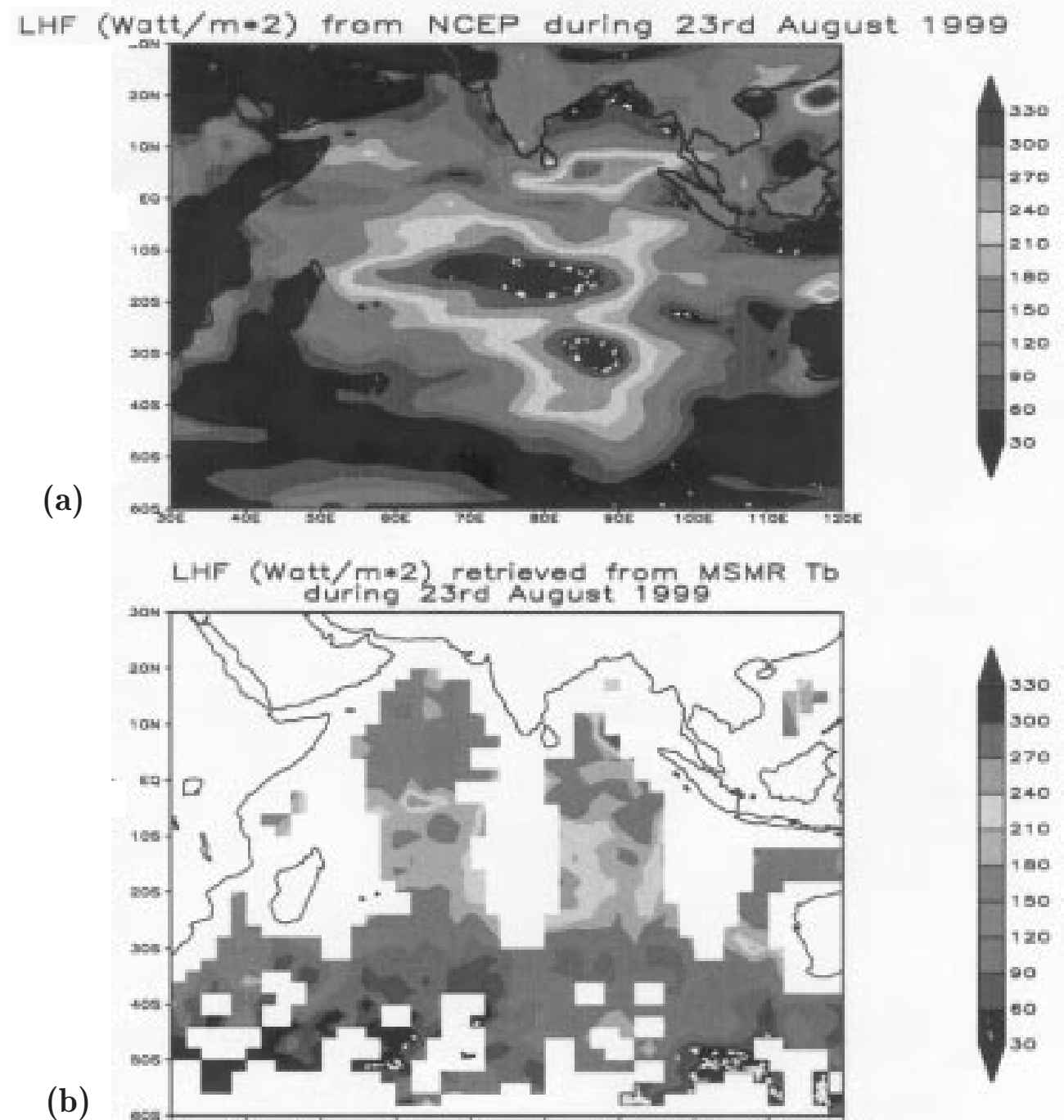

(b)

(c)

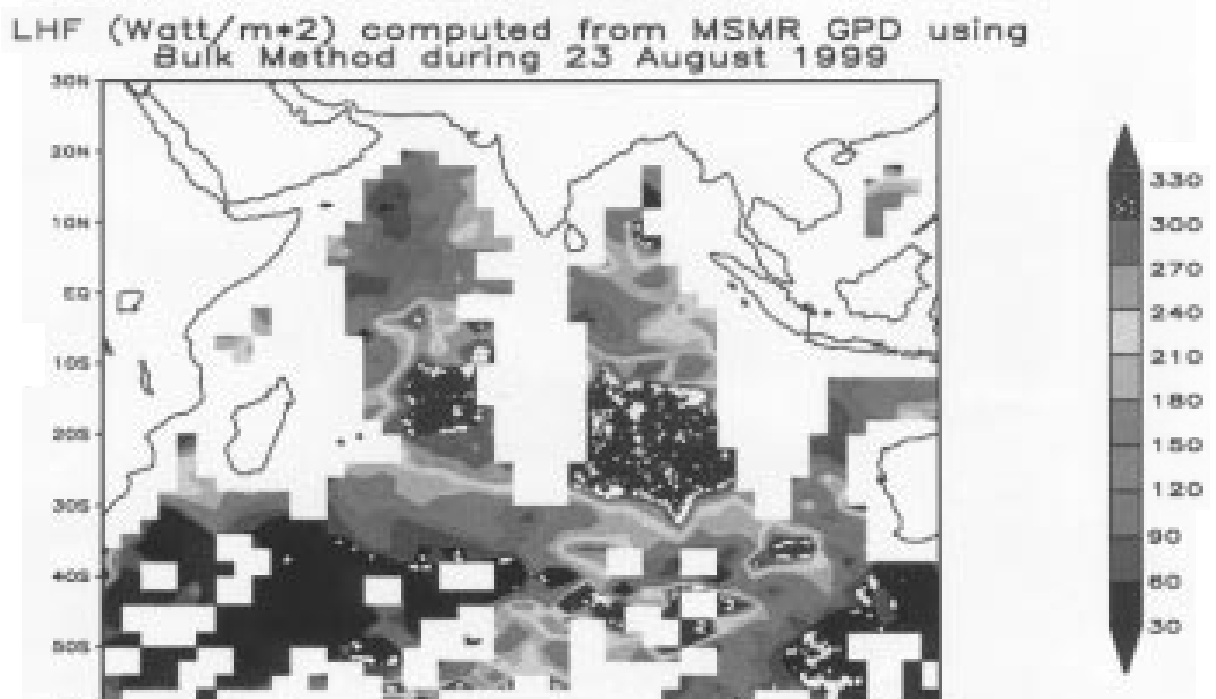

Figure 2. (a) LHF derived using NCEP data; (b) MSMR retrieved LHF using derived coefficients during 23rd August 1999; (c) Same as figure 2(a) but computed using bulk formula. 


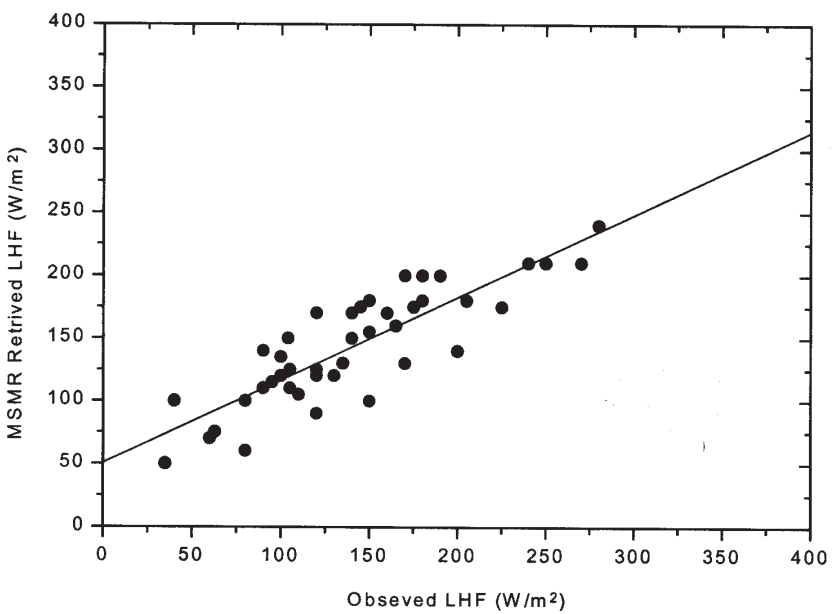

(a)

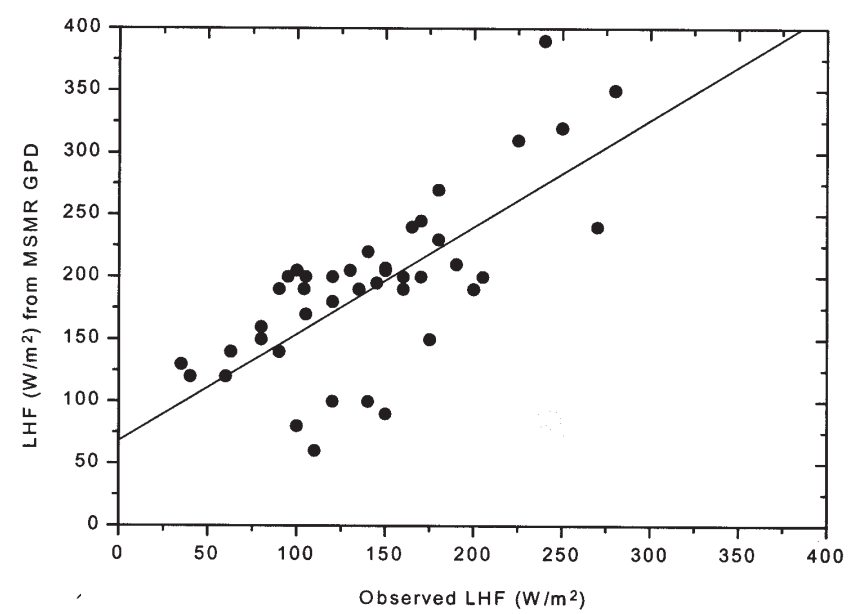

(b)

Figure 3. (a) Comparison between in situ measured LHF and MSMR retrieved LHF for the Indian Ocean; (b) Comparison between in situ measured LHF and computed LHF using bulk formula.

order of $60 \mathrm{~W} / \mathrm{m}^{2}$ have been found. Very near to the coast the MSMR retrieved LHF is noisy due to land influence on the brightness temperatures so we are not taking these pixels into account. The retrieved surface LHF were compared with that computed using in situ observation over the Indian Ocean during June - August 1999. Figure 3(a) shows the scatter plot between observed and retrieved surface LHF. We could get only 43 points for validation purpose. The estimated RMS error is of the order of $35 \mathrm{Wm}^{-2}$. Figure 3(b) shows the scatter plot between observed and the computed flux using bulk formula over Indian Ocean during June - August 1999. The estimated RMS error is of the order of $70 \mathrm{Wm}^{-2}$. This large error in LHF computed using bulk method is probably due to wind retrieval error. Thus we find that the estimation of LHF directly from measured radiance brings down the error significantly.

\section{Conclusions}

The results of the study show that it is possible to use a statistical model to relate directly microwave brightness temperatures to the surface latent heat flux (LHF). Comparisons of the retrieved latent heat flux from MSMR brightness temperature with those of in situ data for three months show that the LHF is retrieved with $35 \mathrm{watt} / \mathrm{m}^{2}$ accuracy. In future we would like to introduce the nonlinear character of LHF with $\mathrm{Tb}$ in developing the algorithm. Finally these fluxes will be used to modify the boundary layer parameterization schemes in numerical models.

\section{Acknowledgements}

One of the authors (Randhir Singh) acknowledges the award of research fellowship under ISRO - Geosphere Biosphere Programme. The NCEP data were made available in useable form by Pradeep Kumar Thapliyal, and is gratefully acknowledged. Authors gratefully acknowledge the discussions with Dr. B S Gohil, the project manager of IRS-P4 geophysical parameters retrievals. Authors are also thankful for fruitful discussions with Dr. M S Narayanan and Dr. Abhijit Sarkar.

\section{References}

Draper N and Smith H 1981 Applied regression analysis $2^{\text {nd }}$ ed, (Wiley: New York)

Esbenson S K, Chelton D B, Vickers D, and Sun J, 1993 An analysis of errors in special sensor microwave imager evaporation estimates over the global oceans; J. Geophys. Res. 98 7081-710

Eymard L, Klapisz R and Bernard R 1989 Comparison between Nimbus-7 SMMR and ECMWF model analysis: The problem of the surface latent heat flux; J. Atmos. Oceanic Technol. 6 866-881

Gohil B S, Varma A K and Mathur A K 2000 Geophysical parameters retrieval over global ocean from IRSP-4 MSMR, Proceeding of International Symposium (Pacific/Ocean Remote Sensing Congress-PORSEC) Goa

Joshi P C and Simon B 1993 Boundary layer modelling and satellite data analysis, presented in ISRO/IGBP workshop, pp 40, Indian Space Research Organization ./Int. Geosphere-Biosphere Programme, Bangalore, India, February.

Liu W T 1986 Statistical relation between monthly mean precipitable water and surface-level humidity over global oceans, Mon. Weather Rev. 114 1591-1602

Liu W T and Niiler P P 1984 Determination of monthly mean humidity in the atmosphere surface layer over the ocean from satellite data; J.Phys. Oceanography 141452 1457

Large W G and Pond S 1952 Open ocean momentum flux measurements in moderates to strong winds; J. Phys. Oceanography 11 324-336

Monin A S and Obukhov A M 1954 Basic laws of turbulent mixing in ground layer of the atmosphere; Akad.Nawk SSSR Geofiz.Inst Tr., 151 163-187 
Singh R, Simon B and Joshi P C 2000 A technique of direct retrieval of surface specific humidity from IRS-P4/MSMR satellite data; Int J. Remote Sensing (submitted).

Schulz J, Jeans M, Stefan E and Schlussel P 1996 Evaluation of satellite derived latent heat flux; J. Climate $102782-$ 2795
Smith S R, Legler $\mathrm{D}$ M and Verzone $\mathrm{K}$ V 1999 Quantifying uncertainties in NCEP in NCEP reanalysis using high-quality research vessel observations; CLIMAR 99, WMO Workshop on Advance in Marine climatology, Vancouver, 8-15 Sept. $223-230$

MS received 30 April 2001; revised 21 July 2001 